\title{
Overexpression of denticleless E3 ubiquitin protein ligase homolog (DTL) is related to poor outcome in gastric carcinoma
}

\author{
Hiroki Kobayashi ${ }^{1, *}$, Shuhei Komatsu ${ }^{1, *}$, Daisuke Ichikawa ${ }^{1}$, Tsutomu Kawaguchi $^{1}$, \\ Shoji Hirajima ${ }^{1}$, Mahito Miyamae ${ }^{1}$, Wataru Okajima ${ }^{1}$, Takuma Ohashi ${ }^{1}$, Toshiyuki \\ Kosuga $^{1}$, Hirotaka Konishi ${ }^{1}$, Atsushi Shiozaki ${ }^{1}$, Hitoshi Fujiwara ${ }^{1}$, Kazuma \\ Okamoto $^{1}$, Hitoshi Tsuda ${ }^{2,3}$, Eigo Otsuji ${ }^{1}$ \\ ${ }^{1}$ Division of Digestive Surgery, Department of Surgery, Kyoto Prefectural University of Medicine, Kawaramachihirokoji, \\ Kamigyo-ku, Kyoto, Japan \\ ${ }^{2}$ Department of Pathology, National Cancer Center Hospital, Tokyo, Japan \\ ${ }^{3}$ Department of Basic Pathology, National Defense Medical College, Saitama, Japan \\ *These authors have contributed equally to this work
}

Correspondence to:

Shuhei Komatsu, e-mail: skomatsu@koto.kpu-m.ac.jp

Keywords: gastric cancer, DTL, prognosis, oncogene, biomarker

Received: March 13, $2015 \quad$ Accepted: October 02, 2015

Published: October 13, 2015

\section{ABSTRACT}

Background: Denticleless E3 ubiquitin protein ligase homolog (DTL) has been identified in amplified region (1q32) of several cancers and has an oncogenic function. In this study, we tested whether DTL acts as a cancer-promoting gene through its activation/overexpression in gastric cancer (GC).

Methods: We analyzed 7 GC cell lines and 100 primary tumors that were curatively resected in our hospital between 2001 and 2003.

Results: Overexpression of the DTL protein was detected in GC cell lines (4/7 cell lines; $57 \%$ ) and primary GC tumor samples (42/100 cases; $42 \%$ ). Knockdown of DTL using several specific siRNAs inhibited the proliferation, migration and invasion in a TP53 mutation-independent manner. Overexpression of the DTL was significantly correlated with lymphatic invasion, deeper tumor depth and higher recurrence rate. Patients with DTL-overexpressing tumors had a worse survival rate than those with non-expressing tumors in overall survival $(P=0.0498$, log-rank test) and disease-free survival ( $P=\mathbf{0 . 0 3 2 4}$, log-rank test). In a multivariate analysis, $D T L$ positivity was independently associated with a worse overall survival $(P=\mathbf{0 . 0 1 0 4}$, hazard ratio 3.7 $[1.36-10.1])$ and disease-free survival $(P=0.0070$ (hazard ratio, $3.9(1.45-10.46))$ following radical gastrectomy.

Conclusions: These findings suggest that DTL overexpression plays a crucial role in tumor cell proliferation and highlights its usefulness as a prognosticator and potential therapeutic target in gastric cancer.

\section{INTRODUCTION}

Gastric cancer is the second leading cause of cancer-related death in the world [1]. Recent advances in diagnostic techniques and peri-operative management have increased the early detection of gastric cancer and decreased the mortality rate. However, patients with advanced disease still frequently develop recurrent disease after extended radical resections and consequently have extremely poor survival rates [2].
Numerous genes have been analyzed in an attempt to understand the molecular mechanisms and to improve clinical outcomes for human gastric cancers; however, only a few genes with frequent alterations have been identified [3]. Mutations of TP53, APC [4], and $E$-cadherin [5], amplification and overexpression of $M E T$ and ERBB2 [6], oncogenic activation of $\beta$-catenin and $K$-ras $[7,8]$, inactivation of the mismatch repair gene hMLH1 associated with microsatellite instability (MSI) [9], and hypermethylation of $p 16$ have been repeatedly 
reported $[10,11]$. As discussed in these reports, studies have attempted to identify the biological factors involved in the malignant potential of gastric cancer. However, in clinical settings, only a few genes have been investigated as therapeutic targets and/or diagnostic biomarkers [12], suggesting that novel genes associated with the progression of gastric cancer need to be identified.

The DTL protein was cloned as a downregulated gene during retinoic acid-induced differentiation of the human embryonal carcinoma cell line NT2 [13]. Several studies have revealed that DTL has an oncogenic function in several types of cancer, such as hepatocellular carcinoma, breast cancer, and Ewing sarcoma [14-16]. Moreover, DTL plays a pivotal role in regulating the protein stability of p53 [17]. DTL was recently reported to have an oncogenic role in gastric carcinogenesis as established by in vitro analyses, and significantly overexpressed in gastric cancer tissues than their adjacent non-cancerous tissues [18]. However, to date, there has been no report on the clinical and prognostic significance of DTL overexpression in primary gastric cancer.

In this study, we show that DTL is frequently overexpressed in gastric cancer cell lines and primary gastric cancer tissues. Overexpression of DTL was a poor prognosticator independent of other prognostic factors. Additionally, we demonstrated that knockdown of DTL suppressed cell proliferation, migration, and invasion of DTL-overexpressing gastric cancer cells in a TP53 mutationindependent manner. Our results provide evidence that DTL could be a promising clinical biomarker for determining malignant properties and a target for molecular therapy in patients with gastric cancer.

\section{RESULTS}

\section{Overexpression of DTL in gastric cancer cell lines}

Western blotting analysis was performed using a DTL-specific antibody to determine DTL protein expression in the gastric cancer cell lines KatoIII, NUGC4, MKN7, HGC27, MKN28, MKN45, and MKN74 (Figure 1A). DTL overexpression was observed in the KatoIII, NUGC4, HGC27, and MKN28 cells (4/7 lines, 57\%), suggesting that the DTL gene is a target for activation in gastric cancer cell lines. A formalin-fixed gastric cancer NUGC4 cell line DTL, in which $>50 \%$ of cells showed staining, was used as a positive control, whereas a formalin-fixed gastric cancer MKN45 cell line with low expression of DTL and NUGC4 staining without the DTL antibody were included as a negative control (Figure 1B).

\section{Suppression of cell proliferation by downregulation of DTL expression}

To gain insight into the potential role of DTL as an oncogene whose overexpression could be associated with gastric carcinogenesis, we first performed a cell proliferation assay using three siRNAs specific to DTL to investigate whether knockdown of DTL expression could suppress the proliferation of gastric cancer cells showing overexpression of the gene (Figure 2A). We performed cell proliferation assays using the HGC27 cell line, which has mutant TP53, and the NUGC4 cell line, which has wild-type TP53, because wild-type p53 is expected to be a more suitable substrate than mutant p53 for DTL [15-17]. The proliferation of both HGC27 and NUGC4 cells was significantly lower than controls at $72 \mathrm{~h}$ after transfection (Figure 2B). The proliferation inhibition rate of HGC27 and NUGC4 cells transfected with siRNA-DTL was $66.3 \%$ and $35.9 \%$, respectively, suggesting that this inhibitory effect is not associated with TP53 mutation status.

\section{Suppression of cell migration and invasion by knockdown of DTL}

Transwell migration and invasion assays were performed to examine the invasive potential of both HGC27 and NUGC4 cells transfected with siRNADTL to migrate under different conditions. An uncoated membrane was used for migration assays, whereas a matrigel-coated membrane was used for invasion assays. The number of cells that migrated into the lower chamber was significantly lower for siRNA-DTLtransfected cells than for siRNA-control-transfected cells under both conditions (Figure 2C), suggesting that DTL may increase the ability of gastric cancer cells to migrate and invade.

\section{Immunohistochemical analysis of DTL expression in the primary gastric cancer tumors}

Because DTL protein was overexpressed in some gastric cancer cell lines, it was hypothesized that DTL was also highly expressed in gastric cancer tissues, playing a role in carcinogenesis and malignant outcome. We examined the clinicopathological significance of DTL expression in primary tumor samples of gastric cancer based on the immunohistochemical staining pattern of this protein. Specific immunostaining of the DTL protein in primary samples was confirmed using gastric cancer cell lines as positive (NUGC4) or negative controls (MKN45) (Figure 1B). Expression of the DTL protein was observed in both the cytoplasm and nucleus of cancer cells. In primary cases, DTL protein expression was negative in most of the non-tumorous gastric mucosal cell population (intensity score 0 ). We divided 100 gastric cancer tumors into a high expression group with both intensity scores $\geq 2$ and $\geq 10 \%$ of tumor cells showing immunopositivity $(n=42(42 \%))$ and a low expression group in intensity scores $\leq 1$ and/or $<10 \%$ of tumor cells showing immunopositivity $(n=58(58 \%))$ according to the intensity of DTL staining among tumor cells 
A

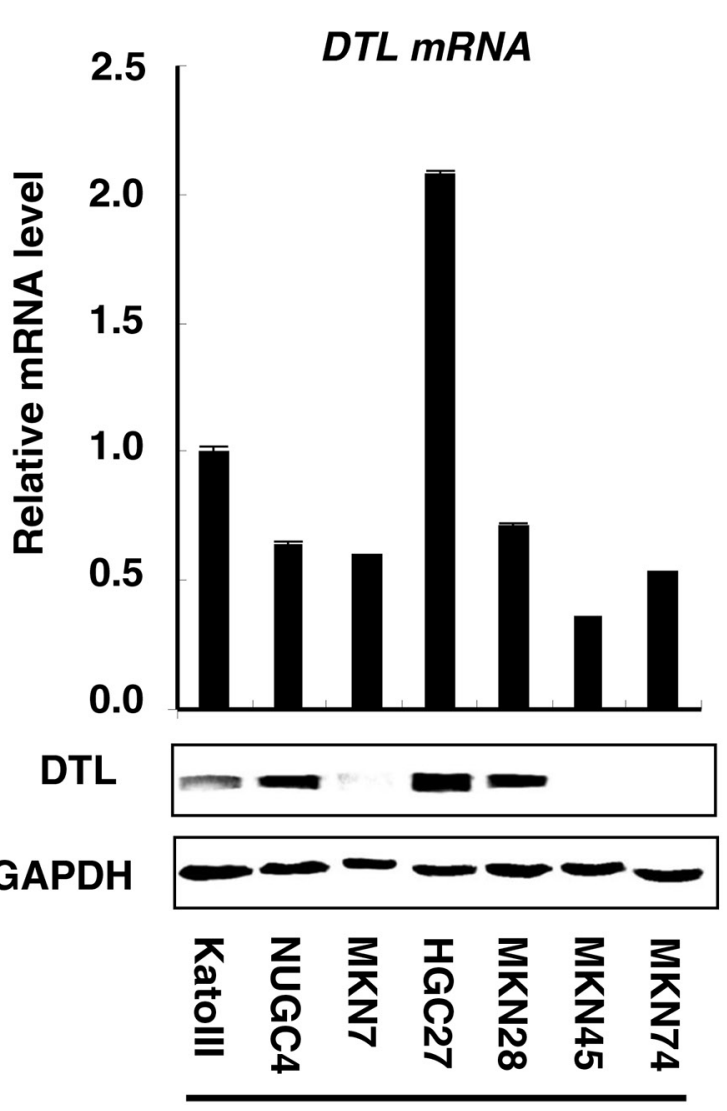

Gastric cancer cell lines
B

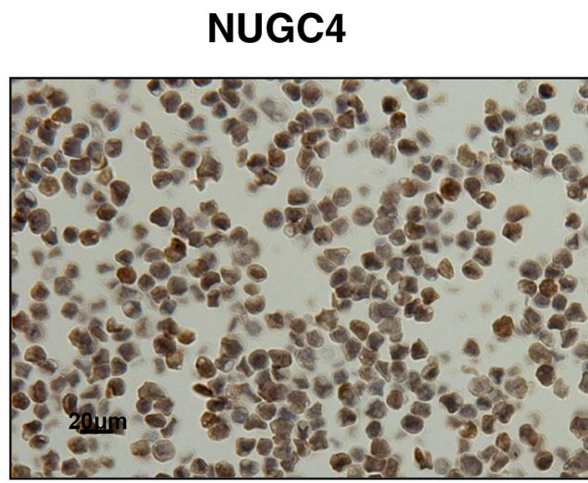

DTL antibody (+)

MKN45

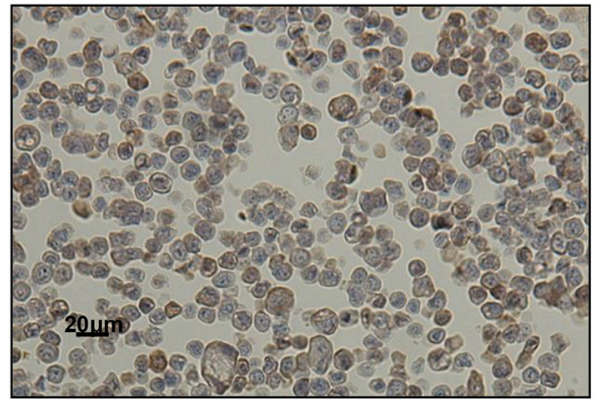

DTL antibody (+)

Figure 1: Expression profiles of DTL in 7 GC cell lines. A. Quantitative real-time RT-PCR and western blotting analysis were performed using a DTL-specific antibody to determine DTL mRNA (top) and protein (bottom) expression in the gastric cancer cell lines KatoIII, NUGC4, MKN7, HGC27, MKN28, MKN45, and MKN74. DTL overexpression was observed in the KatoIII, NUGC4, HGC27, and MKN28 cells (4/7 lines, 57\%). B. A formalin-fixed gastric cancer NUGC4 cell line that overexpresses DTL, in which $>50 \%$ of cells stained positively, was used as a positive control; an MKN45 cell line with a low expression of DTL was included as a negative control.

(Figure 3A). The high expression group had a significantly poorer prognosis than the low expression group for overall survival $(P=0.0498$, log-rank test) (Figure 3B) and disease-free survival $(P=0.0324$, log-rank test $)$ (Figure 3C). Five-year overall survival rates of patients with DTL high- and low-expression cancer in each stage were $95 \%$ vs. $100 \%(p=0.16)$ in stage I, $83 \%$ vs. $67 \%$ ( $p=$ $0.15)$ in stage II and $35 \%$ vs. $54 \%(p=0.22)$ in stage III, respectively.

\section{Association between DTL protein levels and clinicopathological characteristics in primary gastric cancer}

The relationship between the expression of the DTL protein and clinicopathological characteristics is summarized in Table 1. The protein expression of DTL was significantly associated with lymphatic invasion $(P=0.0137)$, deeper depth of invasion $(P=0.0256)$, and recurrence rate $(P=0.0199)$, whereas other characteristics, including histological grade, were not. In the Cox proportional hazard regression model (Table 2), univariate analyses demonstrated that DTL protein expression, macroscopic appearance, venous invasion, lymphatic invasion, $\mathrm{pT}$ category, $\mathrm{pN}$ category, and tumor size were significantly associated with cause-specific survival. When the data were stratified for multivariate analysis using both forward and backward stepwise Cox regression procedures, DTL immunoreactivity in tumor cells remained significant at $P=0.0104$ (hazard ratio, 3.7 (1.36-10.11)) for overall survival (Table 2) and $P=0.0070$ (hazard ratio, 3.9 (1.45-10.46)) for disease-free survival (Supplementary Table S1) in all patients, suggesting that DTL immunoreactivity can be an independent predictor of overall survival.

\section{DISCUSSION}

The DTL gene, which is also known as the CDT2/ $R A M P / D C A F 2 / L 2 D T L$ gene, is located on chromosome $1 \mathrm{q} 32$; this area is frequently amplified in human solid cancers [19]. DTL encodes a putative 730 amino acid 

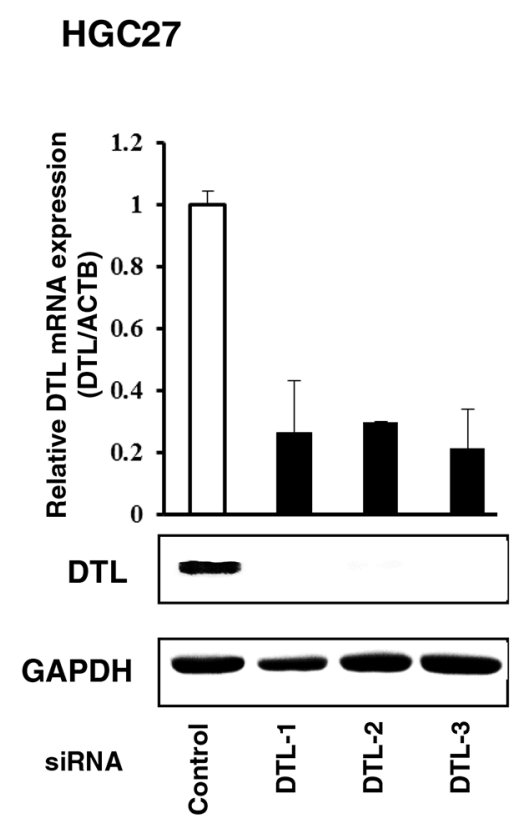

B

HGC27 (mutant TP53)

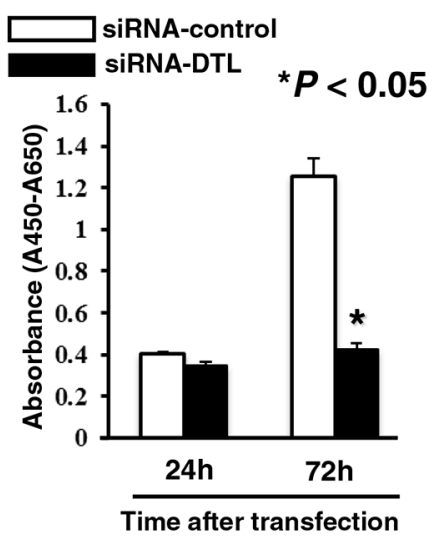

NUGC4 (wild-type TP53)

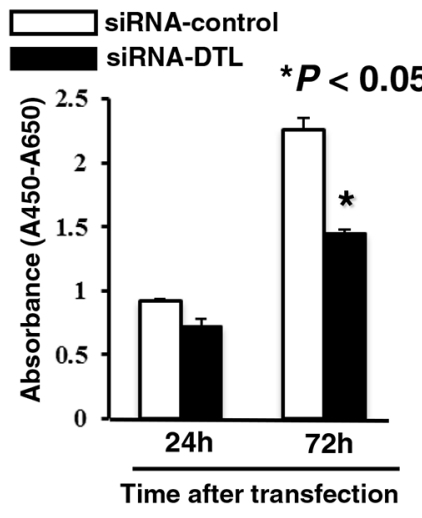

C
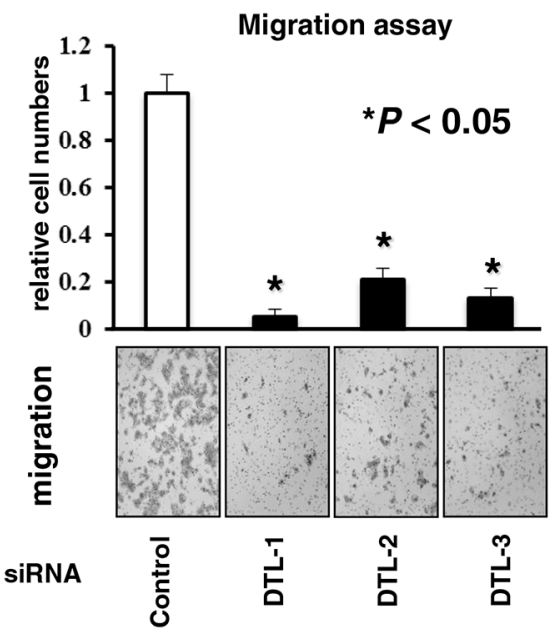

D

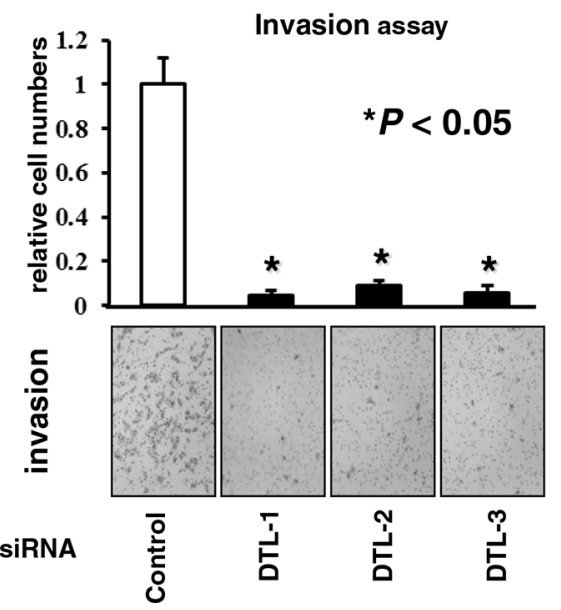

Figure 2: Effects of downregulation of DTL expression. A. Loss-of-function screening was undertaken using three small interfering RNAs (siRNAs) targeting DTL in the HGC27 cell. The knockdown of a target DTL gene was confirmed by quantitative real-time RT-PCR (top) and western blotting (bottom). B. To assess cell growth, the numbers of viable cells at various time points after transfection were assessed by the colorimetric water-soluble tetrazolium salt (WST) assay in the HGC27 (mutant TP53) and NUGC4 (wild-type TP53) cell lines. C. Transwell migration (upper) and invasion (lower) assays using three siRNAs targeting DTL.

protein that contains six highly conserved five WD40repeat domains and physically interacts with the DDB1/ CULLIN4 complex (CRL4). Cullin-RING ubiquitin ligases (CRLs) are the largest family of E3 ligase. DTL is a substrate-specific adapter of CRL4 (CRL4 $\left.{ }^{\text {DTL}}\right)$ and mediates the polyubiquitination and subsequent degradation of CDT1 [20-22], p12 [23], p21 [24-26], SET8 [27-29] and Gen5 [30]. In addition, CRL4 ${ }^{\text {DTL }}$ was shown to promote degradation in some of these substrates, such as CDT1 [20], p21 [24], and SET8 [27] by interaction with PCNA. These molecular mechanisms indicate that DTL has a crucial physiological role. Moreover, DTL has been identified as a clinically relevant factor for enhanced metastatic potential in HCC [14] and tumor growth of breast cancer cells [15] and is highly proliferative in Ewing sarcoma [16]. These findings prompted us to determine the clinicopathological and prognostic significance of DTL overexpression/activation in primary gastric cancer. However, to date, there has been no report on the clinical significance of DTL in patients with primary gastric cancer.

In this study, we hypothesized that the overexpression/ activation of DTL may promote tumor cell proliferation and/or survival in gastric cancer cells. To test this hypothesis, we examined the expression status of DTL and the clinicopathological parameters, as well as the biological significance of its expression in gastric cancer cell lines and primary tumor tissues of gastric cancer. We demonstrated that DTL was overexpressed in $48 \%(29 / 60)$ of primary gastric cancer tissues and 57\% (4/7) of gastric cancer cell lines and that this overexpression was a poor prognosticator independent of other prognostic factors. The prognosis of gastric cancer patients was associated with the intensity of DTL activity. In addition, downregulation of DTL expression suppressed cell proliferation, migration, and invasion in gastric cancer cell lines. 

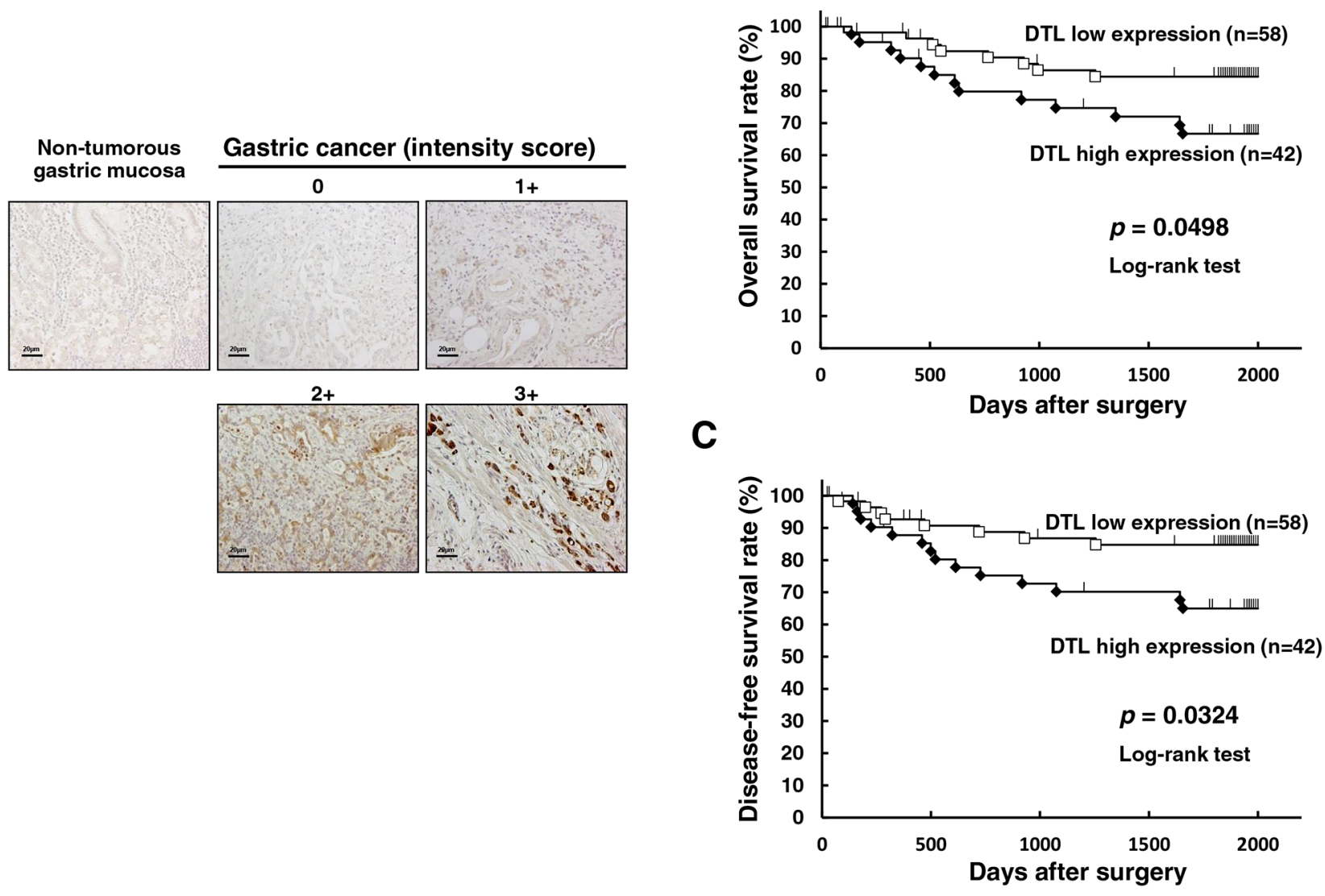

Figure 3: Immunohistochemical-staining analyses and postoperative overall survival curve according to the expression of DTL. A. Specific immunostaining of the DTL protein in primary samples was confirmed. Expression of the DTL protein was observed in both the cytoplasm and nucleus of cancer cells. For scoring DTL expression, the intensity score was defined as $0=$ negative, $1=$ weak, $2=$ moderate, $3=$ strong. The DTL high expression group had a significantly poorer prognosis than the low expression group in overall survival $(P=0.0498, \log$-rank test $) \mathbf{B}$. and disease-free survival $(P=0.0324, \log$-rank test $)$ C.

While investigating the interaction between DTL and p53, Banks et al. reported that DTL and PCNA regulate $\mathrm{p} 53$ polyubiquitination, and the inactivation of DTL induces p53 stabilization and cell growth arrest [17]. Li et al. reported that DTL-mediated apoptosis in gastric cancer cells is dependent on the p53 pathway [18]. Pan et al. reported that DTL overexpression was associated with poor prognosis, particularly in TP53-mutated hepatocellular carcinoma cell lines [14]. In our study, knockdown using several siRNAs specific to DTL in DTL-expressing gastric cancer cells significantly reduced cell proliferation in a TP53 mutation-independent manner. In addition, migration and invasion were inhibited.

Our results indicate that DTL plays a crucial role in tumor cell proliferation, migration and invasion through a p53-dependent or independent pathway.

In conclusion, this is the first report demonstrating that DTL has a pivotal oncogenic role independent of TP53 mutation and is an independent poor prognostic factor in gastric cancer. Although studies of larger cohorts are needed to validate these findings before moving to a clinical setting, our results suggest that DTL is an important molecular marker for determining malignant properties and targets for molecular therapy in patients with this lethal disease.

\section{MATERIALS AND METHODS}

\section{Gastric cancer cell lines and primary tissue samples}

Seven gastric cancer cell lines, KatoIII, NUGC4, HGC27, MKN7, MKN28, MKN45 and MKN74, were used in these studies. HGC27 cells were cultured in Dulbecco's Minimum Essential Medium (DMEM): F12 medium, and the other cells were cultured in Roswell Park Memorial Institute (RPMI)-1640 medium (Sigma, St. Louis, MO). All media were purchased from Sigma and supplemented with $100 \mathrm{~mL} / \mathrm{L}$ FBS (Trace Scientific, Melbourne, Australia). All cell lines were cultured in $50 \mathrm{~mL} / \mathrm{L}$ carbon dioxide at $37^{\circ} \mathrm{C}$ in a humidified chamber. Primary gastric cancer tumor samples were 
Table 1: Association between clinicopathologic characteristics and DTL expression

\begin{tabular}{|c|c|c|c|c|}
\hline & \multirow[t]{2}{*}{$n$} & \multicolumn{2}{|c|}{ DTL immunoreactivity } & \multirow[t]{2}{*}{$P$ value* } \\
\hline & & high expression & low expression & \\
\hline Total & 100 & $42(42 \%)$ & $58(58 \%)$ & \\
\hline \multicolumn{5}{|l|}{ Gender } \\
\hline Male & 59 & $29(69 \%)$ & $30(52 \%)$ & 0.0821 \\
\hline Female & 41 & $13(31 \%)$ & $28(48 \%)$ & \\
\hline \multicolumn{5}{|l|}{ Age (y) } \\
\hline \multicolumn{5}{|c|}{ Mean 61.22 (range:28-87) } \\
\hline$<60$ & 40 & $16(38 \%)$ & $24(41 \%)$ & 0.7407 \\
\hline$\geq 60$ & 60 & $26(62 \%)$ & $34(59 \%)$ & \\
\hline \multicolumn{5}{|c|}{ Histopathological grading } \\
\hline Differentiated & 45 & $20(48 \%)$ & $25(43 \%)$ & 0.6542 \\
\hline Undifferentiated & 55 & $22(52 \%)$ & $33(57 \%)$ & \\
\hline \multicolumn{5}{|l|}{ Tumor size (mm) } \\
\hline$<25$ & 32 & $12(28 \%)$ & $20(34 \%)$ & 0.5317 \\
\hline$\geq 25$ & 68 & $30(72 \%)$ & $38(66 \%)$ & \\
\hline \multicolumn{5}{|l|}{ Venous invasion } \\
\hline v0 & 72 & $27(64 \%)$ & $45(78 \%)$ & 0.1462 \\
\hline v1-2 & 25 & $15(36 \%)$ & $10(17 \%)$ & \\
\hline v3 & 3 & $0(0 \%)$ & $3(5 \%)$ & \\
\hline \multicolumn{5}{|l|}{ Lymphatic invasion } \\
\hline ly0 & 55 & $16(38 \%)$ & $39(67 \%)$ & 0.0137 \\
\hline ly $1-2$ & 39 & $24(57 \%)$ & $15(26 \%)$ & \\
\hline ly3 & 6 & $2(5 \%)$ & $4(7 \%)$ & \\
\hline \multicolumn{5}{|l|}{ TNM classification } \\
\hline \multicolumn{5}{|l|}{ pT categories } \\
\hline pT1-3 & 78 & $28(67 \%)$ & $50(81 \%)$ & 0.0199 \\
\hline pT4 & 22 & $14(33 \%)$ & $8(19 \%)$ & \\
\hline \multicolumn{5}{|l|}{ pN categories } \\
\hline pN0-2 & 84 & $33(79 \%)$ & $51(86 \%)$ & 0.2076 \\
\hline $\mathrm{pN} 3$ & 16 & $9(21 \%)$ & 7 (14\%) & \\
\hline \multicolumn{5}{|l|}{ Recurrennce } \\
\hline Absent & 78 & $28(67 \%)$ & $50(81 \%)$ & 0.0199 \\
\hline Present & 22 & $14(33 \%)$ & $8(19 \%)$ & \\
\hline
\end{tabular}

NOTE. Significant values are in bold type.

$* P$ values are from $\chi^{2}$ or Fisher's exact test and were significant at $<0.05$.

obtained from 100 consecutive gastric cancer patients who underwent curative gastrectomy (R0) at the Division of Digestive Surgery, Department of Surgery, Kyoto Prefectural University of Medicine (Kyoto, Japan) between 2001 and 2003 and were embedded in paraffin after $24 \mathrm{~h}$ of formalin fixation. Relevant clinical and survival data were available for all patients. Written consent was always obtained in a formal style and 
Table 2: Multivariate analysis for overall survival using stepwise Cox regression procedures

\begin{tabular}{|c|c|c|c|c|c|c|}
\hline \multirow[t]{2}{*}{ Variables } & \multirow{2}{*}{$\frac{\text { Univariate }^{\mathrm{a}}}{P \text { value }}$} & \multicolumn{5}{|c|}{ Multivariate $^{\mathrm{b}}$} \\
\hline & & $H^{c}$ & & $95 \% \mathrm{CI}^{\mathrm{d}}$ & & $P$ value \\
\hline \multicolumn{7}{|l|}{ Gender } \\
\hline male versus female & 0.8990 & & & - & & \\
\hline \multicolumn{7}{|l|}{ Age } \\
\hline$\geq 60$ versus $<60$ & 0.7325 & & & - & & \\
\hline \multicolumn{7}{|l|}{ Histological type } \\
\hline Undiffe.versus Diffe. & 0.7982 & & & - & & \\
\hline \multicolumn{7}{|l|}{ Tumor size (mm) } \\
\hline$\geq 25$ versus $<25$ & $<0.0005$ & & & - & & \\
\hline \multicolumn{7}{|l|}{ Venous invasion } \\
\hline v2-3 versus v0-1 & $<0.005$ & & & - & & \\
\hline \multicolumn{7}{|l|}{ Lymphatic invasion } \\
\hline ly2-3 versus $1 y 0-1$ & $<0.0001$ & 12.74 & 4.045 & - & 40.05 & $<0.0001$ \\
\hline \multicolumn{7}{|l|}{ pT-stage } \\
\hline $\mathrm{T} 4$ versus $\mathrm{T} 1-3$ & $<0.0001$ & & & - & & \\
\hline \multicolumn{7}{|l|}{ pN-stage } \\
\hline $\mathrm{N} 3$ versus $\mathrm{N} 0-2$ & $<0.0001$ & 7.591 & 2.661 & - & 21.65 & 0.0002 \\
\hline \multicolumn{7}{|l|}{ DTL expression } \\
\hline high versus low & 0.0499 & 3.709 & 1.360 & - & 10.11 & 0.0104 \\
\hline
\end{tabular}

a Kaplan and Meier method, and the statistical significance was determined by log-rank test

${ }^{b}$ Multivariate survival analysis was performed using Cox's proportional hazard model

${ }^{\mathrm{c}} \mathrm{HR}$ :hazard ratio

${ }^{\mathrm{d}} \mathrm{CI}$ :confidence interval

after approval by the local Ethics Committee. None of the patients underwent endoscopic mucosal resection, palliative resection, preoperative chemotherapy, or radiotherapy, and none of them had synchronous or metachronous multiple cancers in other organs. Disease stage was defined in accordance with the International Union against Cancer tumor-lymph node-metastases (TNM) classification (7th edition) [31]. The median follow-up period for surviving patients was 105.1 months (ranging from 0.8 to 163.5 months).

\section{Quantitative real-time RT-PCR}

Single-stranded complementary DNAs generated from total RNA were amplified with primers specific for each gene. Levels of messenger RNA (mRNA) expression were measured by quantitative real-time fluorescence detection (ABI StepOnePlus ${ }^{\mathrm{TM}}$ Sequence Detection System; Applied Biosystems, Foster City, CA) using TaqMan Gene Expression Assays (Hs00978565 m1 for DTL; Applied Biosystems) according to the manufacturer's instructions. The results of gene expression were calculated as the ratio between DTL and an internal reference gene (Hs99999903_m1 for $\beta$-actin; Applied Biosystems) that provides a normalization factor for the amount of RNA isolated from a specimen. The ratio was subsequently normalized to the KatoIII cell line (relative expression). This assay was performed in duplicate for each sample.

\section{Western blotting}

Anti-DTL rabbit polyclonal antibody (NB10040840) was purchased from Novus Biologicals, LLC (Colorado, USA) and anti-GAPDH antibody was purchased from Santa Cruz Biotechnology (Santa Cruz, CA). DTL antibody is an affinity purified rabbit polyclonal antibody raised against the recombinant peptide containing a portion of the DTL protein with a His-tag at its C-terminus. The cells were lysed, and their proteins were extracted using the M-PER ${ }^{\circledR}$ Mammalian Protein Extraction Reagent (Thermo Scientific, USA). 


\section{Loss-of-function by small interfering RNA (siRNA) and cell growth analysis}

For knocking down endogenous DTL expression, each of the small interfering RNAs (siRNA) targeting DTL (Stealth RNAi ${ }^{\text {TM}}$, siRNA-DTL-1; \# HSS122293, siRNA-DTL-2; \# HSS122295 and siRNA-DTL-3; \# HSS182090; Invitrogen, Carlsbad, CA) and the control were transfected into cells $(10 \mathrm{nmol} / \mathrm{l})$ using Lipofectamine RNAiMAX (Invitrogen, Carlsbad, CA) according to the manufacturer's instructions. The knockdown of a target gene was confirmed by quantitative real-time RT-PCR and western blotting. To measure cell proliferation, the number of viable cells 24 and $72 \mathrm{~h}$ after siRNA transfection was assessed by the colorimetric water-soluble tetrazolium salt (WST) assay (Cell counting kit-8; Dojindo Laboratories, Kumamoto, Japan) [32].

\section{Transwell migration and invasion assays}

Transwell migration and invasion assays were carried out in 24-well modified Boyden chambers (transwell-chamber, BD Transduction, Franklin Lakes, NJ). The upper surface of the $6.4 \mathrm{~mm}$ diameter filters with $8-\mu \mathrm{m}$ pores was pre-coated with (invasion assay) or without (migration assay) Matrigel (BD Transduction). The siRNA transfectants $\left(2 \times 10^{4}\right.$ cells per well $)$ were transferred into the upper chamber. Following $48 \mathrm{~h}$ of incubation, migrated or invasive cells on the lower surface of filters were fixed and stained with the Diff-Quik stain (Sysmex, Kobe, Japan), and stained cell nuclei were counted directly in triplicate. We assessed the invasive potential by calculating the ratio of the percentage invasion through the Matrigel-coated filters relative to migration through the uncoated filters of test cells over that in the control counterparts $[33,34]$.

\section{Immunohistochemistry}

Anti-DTL rabbit polyclonal antibody (NB10040840), which was the same antibody as western blotting analysis and was purchased from Novus Biologicals, LLC (Colorado, USA), was used. Tumor samples were fixed with $10 \%$ formaldehyde in PBS, embedded in paraffin, sectioned into $5-\mu \mathrm{m}$-thick slices, and subjected to immunohistochemical staining of the DTL protein with the avidin-biotin-peroxidase method as described by Naoi et al. [35]. In brief, after deparaffinization, endogenous peroxidases were quenched by incubating the sections for $30 \mathrm{~min}$ in $3 \% \mathrm{H}_{2} \mathrm{O}_{2}$. Antigen retrieval was performed by heating the samples in $10 \mathrm{mmol} / \mathrm{L}$ citrate buffer $(\mathrm{pH}$ 6.0 ) at $95^{\circ} \mathrm{C}$ for $60 \mathrm{~min}$. After treatment with Block Ace (Dainippon Sumitomo Pharmaceutical, Osaka, Japan) for $20 \mathrm{~min}$ at room temperature, sections were incubated at $4^{\circ} \mathrm{C}$ overnight with an anti-DTL $(1: 1000)$ antibody. The avidin-biotin-peroxidase complex system (Vectastain
Elite $\mathrm{ABC}$ universal kit; Vector Laboratories Inc., Burlingame, CA) was used for color development with diaminobenzidine tetrahydrochloride. The slides were counterstained with Mayer's hematoxylin. A formalinfixed gastric cancer NUGC4 cell line that overexpresses DTL, in which $>50 \%$ of cells stained positive, was used as a positive control, whereas a formalin-fixed gastric cancer MKN45 cell line with low expression of DTL was included as a negative control.

To evaluate DTL expression, in the percentage of tumor cells showing DTL immunopositivity, primary tumors with at least $10 \%$ or more of the total cell population was judged positive, and less than $10 \%$ was judged negative. In the intensity of DTL expression, the intensity score $(0=$ negative, $1=$ weak, $2=$ moderate, 3 strong) was examined. Namely, primary tumors with non-detectable DTL expression, which was similar to non-tumorous gastric mucosa and stroma, were given an intensity score of 0 , whereas those with the greatest DTL abundance were given an intensity score of 3 . The remaining tumors were categorized with intensity scores of 1 or 2 according to the intensity of immunohistochemical staining for DTL. The expression of DTL was regarded as high expression in both intensity scores $\geq 2$ and $\geq 10 \%$ of tumor cells showing immunopositivity or low expression in intensity scores $\leq 1$ and $/$ or $<10 \%$ using high-powered (x 200) microscopy [36, 37].

\section{Statistical analysis}

Clinicopathological variables pertaining to the corresponding patients were analyzed for statistical significance using the chi-squared test or Fisher's exact test. For the analysis of survival, Kaplan-Meier survival curves were constructed for groups based on univariate predictors, and differences between the groups were analyzed with the log-rank test. Univariate and multivariate survival analyses were performed using the likelihood ratio test of the stratified Cox proportional hazards model. Differences between subgroups were tested with the non-parametric Mann-Whitney $U$-test. Differences were assessed with a two-sided test and were considered statistically significant at $P<0.05$.

\section{CONFLICTS OF INTEREST}

All authors declare no potential conflict of interest.

\section{REFERENCES}

1. Parkin DM, Bray F, Ferlay J, Pisani P. Global cancer statistics, 2002. CA Cancer J Clin. 2005; 55:74-108.

2. Martin RC 2nd, Jaques DP, Brennan MF, Karpeh M. Extended local resection for advanced gastric cancer: increased survival versus increased morbidity. Ann Surg. 2002; 236:159-65. 
3. Ushijima T, Sasako M. Focus on gastric cancer. Cancer cell. 2004; 5:121-5.

4. Maesawa C, Tamura G, Suzuki Y, Ogasawara S, Sakata K, Kashiwaba M, Satodate R. The sequential accumulation of genetic alterations characteristic of the colorectal adenoma-carcinoma sequence does not occur between gastric adenoma and adenocarcinoma. J Pathol. 1995; 176:249-58.

5. Becker KF, Atkinson MJ, Reich U, Becker I, Nekarda H, Siewert JR, Höfler H. E-cadherin gene mutations provide clues to diffuse type gastric carcinomas. Cancer Res. 1994; 54:3845-52.

6. Nakajima M, Sawada H, Yamada Y, Watanabe A, Tatsumi M, Yamashita J, Matsuda M, Sakaguchi T, Hirao T, Nakano H. The prognostic significance of amplification and overexpression of c-met and c-erb B-2 in human gastric carcinomas. Cancer. 1999; 85:1894-902.

7. Lee JH, Abraham SC, Kim HS, Nam JH, Choi C, Lee MC, Park CS, Juhng SW, Rashid A, Hamilton SR, Wu TT. Inverse relationship between APC gene mutation in gastric adenomas and development of adenocarcinoma. Am J Pathol. 2002; 161:611-8.

8. Park WS, Oh RR, Park JY, Lee SH, Shin MS, Kim YS, Kim SY, Lee HK, Kim PJ, Oh ST, Yoo NJ, Lee JY. Frequent somatic mutations of the beta-catenin gene in intestinal-type gastric cancer. Cancer Res. 1999; 59:4257-60.

9. Fang DC, Wang RQ, Yang SM, Yang JM, Liu HF, Peng GY, Xiao TL, Luo YH. Mutation and methylation of hMLH1 in gastric carcinomas with microsatellite instability. World journal of gastroenterology: WJG. 2003; 9:655-9.

10. Ding Y, Le XP, Zhang QX, Du P. Methylation and mutation analysis of p16 gene in gastric cancer. World J Gastroenterol. 2003; 9:423-6.

11. Oue N, Motoshita J, Yokozaki H, Hayashi K, Tahara E, Taniyama K, Matsusaki K, Yasui W. Distinct promoter hypermethylation of p16INK4a, CDH1, and RAR-beta in intestinal, diffuse-adherent, and diffuse-scattered type gastric carcinomas. J Pathol. 2002; 198:55-9.

12. Bang YJ, Van Cutsem E, Feyereislova A, Chung HC, Shen L, Sawaki A, Lordick F, Ohtsu A, Omuro Y, Satoh T, Aprile G, Kulikov E, Hill J, et al. Trastuzumab in combination with chemotherapy versus chemotherapy alone for treatment of HER2-positive advanced gastric or gastrooesophageal junction cancer (ToGA): a phase 3, open-label, randomised controlled trial. Lancet. 2010; 376:687-97.

13. Cheung WM, Chu AH, Chu PW, Ip NY. Cloning and expression of a novel nuclear matrix-associated protein that is regulated during the retinoic acid-induced neuronal differentiation. J Biol Chem. 2001; 276:17083-91.

14. Pan HW, Chou HY, Liu SH, Peng SY, Liu CL, Hsu HC. Role of L2DTL, cell cycle-regulated nuclear and centrosome protein, in aggressive hepatocellular carcinoma. Cell Cycle. 2006; 5:2676-87.

15. Ueki T, Nishidate T, Park JH, Lin ML, Shimo A, Hirata K, Nakamura Y, Katagiri T. Involvement of elevated expression of multiple cell-cycle regulator, DTL/RAMP (denticleless/RA-regulated nuclear matrix associated protein), in the growth of breast cancer cells. Oncogene. 2008; 27:5672-83.

16. Mackintosh C, Ordóñez JL, García-Domínguez DJ, Sevillano V, Llombart-Bosch A, Szuhai K, Scotlandi K, Alberghini M, Sciot R, Sinnaeve F, Hogendoorn PC, Picci P, Knuutila S, et al. 1q gain and CDT2 overexpression underlie an aggressive and highly proliferative form of Ewing sarcoma. Oncogene. 2012; 31:1287-98.

17. Banks D, Wu M, Higa LA, Gavrilova N, Quan J, Ye T, Kobayashi R, Sun H, Zhang H. L2DTL/CDT2 and PCNA interact with $\mathrm{p} 53$ and regulate $\mathrm{p} 53$ polyubiquitination and protein stability through MDM2 and CUL4A/DDB1 complexes. Cell Cycle. 2006; 5:1719-29.

18. Li J, Ng EK, Ng YP, Wong CY, Yu J, Jin H, Cheng VY, Go MY, Cheung PK, Ebert MP, Tong J, To KF, Chan FK, et al. Identification of retinoic acid-regulated nuclear matrix-associated protein as a novel regulator of gastric cancer. Br J Cancer. 2009; 101:691-8.

19. Rooney PH, Murray GI, Stevenson DA, Haites NE, Cassidy J, McLeod HL. Comparative genomic hybridization and chromosomal instability in solid tumours. Br J Cancer. 1999; 80:862-73.

20. Higa LA1, Banks D, Wu M, Kobayashi R, Sun H, Zhang H. L2DTL/CDT2 interacts with the CUL4/DDB1 complex and PCNA and regulates CDT1 proteolysis in response to DNA damage. Cell Cycle. 2006; 5:1675-80.

21. Sansam CL, Shepard JL, Lai K, Ianari A, Danielian PS, Amsterdam A, Hopkins N, Lees JA. DTL/CDT2 is essential for both CDT1 regulation and the early G2/M checkpoint. Genes Dev. 2006; 20:3117-29.

22. Jin J, Arias EE, Chen J, Harper JW, Walter JC. A family of diverse Cul4-Ddb1-interacting proteins includes Cdt2, which is required for $\mathrm{S}$ phase destruction of the replication factor Cdt1. Mol Cell. 2006; 23:709-21.

23. Terai K, Shibata E, Abbas T, Dutta A. Degradation of p12 subunit by CRL4Cdt2 E3 ligase inhibits fork progression after DNA damage. J Biol Chem. 2013; 288:30509-14.

24. Abbas T, Sivaprasad U, Terai K, Amador V, Pagano M, Dutta A. PCNA-dependent regulation of p21 ubiquitylation and degradation via the CRL4Cdt2 ubiquitin ligase complex. Genes Dev. 2008; 22:2496-506.

25. Nishitani H, Shiomi Y, Iida H, Michishita M, Takami T, Tsurimoto T. CDK inhibitor p21 is degraded by a proliferating cell nuclear antigen-coupled Cul4-DDB1Cdt2 pathway during S phase and after UV irradiation. J Biol Chem. 2008; 283:29045-52.

26. Kim Y, Starostina NG, Kipreos ET. The CRL4Cdt2 ubiquitin ligase targets the degradation of p21Cip1 to control replication licensing. Genes Dev. 2008; 22:2507-19.

27. Jørgensen $\mathrm{S}$, Eskildsen $\mathrm{M}$, Fugger $\mathrm{K}$, Hansen L, Larsen MS, Kousholt AN, Syljuåsen RG, Trelle MB, Jensen ON, Helin K, Sørensen CS. SET8 is degraded via 
PCNA-coupled CRL4(CDT2) ubiquitylation in S phase and after UV irradiation. J Cell Biol. 2011; 192:43-54.

28. Oda H, Hübner MR, Beck DB, Vermeulen M, Hurwitz J, Spector DL, Reinberg D. Regulation of the histone H4 monomethylase PR-Set7 by CRL4(Cdt2)-mediated PCNAdependent degradation during DNA damage. Mol Cell. 2010; 40:364-76.

29. Centore RC, Havens CG, Manning AL, Li JM, Flynn RL, Tse A, Dyson NJ, Walter JC, Zou L. CRL4(Cdt2)-mediated destruction of the histone methyltransferase Set8 prevents premature chromatin compaction in S phase. Mol Cell. 2010; 40:22-33.

30. Li Y, Jaramillo-Lambert A, Hao J, Yang Y, Zhu W. The stability of histone acetyltransferase general control nonderepressible (Gcn) 5 is regulated by Cullin4-RING E3 ubiquitin ligase. J Biol Chem. 2011; 286:41344-52.

31. Sobin LH GM, Wittekind C. TNM classification of Malignant Tumors. New York: Wiley-liss(7th edition)2009.

32. Komatsu S, Imoto I, Tsuda H, Kozaki KI, Muramatsu T, Shimada Y, Aiko S, Yoshizumi Y, Ichikawa D, Otsuji E, Inazawa J. Overexpression of SMYD2 relates to tumor cell proliferation and malignant outcome of esophageal squamous cell carcinoma. Carcinogenesis. 2009; 30:1139-46.
33. Kashimoto K, Komatsu S, Ichikawa D, Arita T, Konishi H, Nagata H, Takeshita H, Nishimura Y, Hirajima S, Kawaguchi T, Shiozaki A, Fujiwara H, Okamoto K, et al. Overexpression of TRIM44 contributes to malignant outcome in gastric carcinoma. Cancer Sci. 2012; 103:2021-6.

34. Nishimura $Y$, Komatsu S, Ichikawa D, Nagata $H$, Hirajima S, Takeshita H, Kawaguchi T, Arita T, Konishi H, Kashimoto K, Shiozaki A, Fujiwara H, Okamoto K, et al. Overexpression of YWHAZ relates to tumor cell proliferation and malignant outcome of gastric carcinoma. Br J Cancer. 2013; 108:1324-31.

35. Naoi Y, Miyoshi Y, Taguchi T, Kim SJ, Arai T, Maruyama N, Tamaki Y, Noguchi S. Connexin26 expression is associated with aggressive phenotype in human papillary and follicular thyroid cancers. Cancer Lett. 2008; 262:248-56.

36. Tsuda H. Individualization of breast cancer based on histopathological features and molecular alterations. Breast cancer. 2008; 15:121-32.

37. Komatsu S, Ichikawa D, Hirajima S, Nagata $H$, Nishimura Y, Kawaguchi T, Miyamae M, Okajima W, Ohashi T, Konishi H, Shiozaki A, Fujiwara H, Okamoto K, et al. Overexpression of SMYD2 contributes to malignant outcome in gastric cancer. Br J Cancer. 2015; 112:357-64. 